\title{
A Novel c.554+5C>T Mutation in the DUOXA2 Gene Combined with p.R885Q Mutation in the DUOX2 Gene Causing Congenital Hypothyroidism
}

\author{
Xiao Zheng1, Shao-Gang Ma1, Ya-Li Qiu2, Man-Li Guo1, Xiao-Juan Shao1 \\ 1Huai'an Hospital Affiliated to Xuzhou Medical College and Huai'an Second People's Hospital, Clinic of Endocrinology and Metabolism, Huai'an, China \\ 2 Women and Children's Hospital of Suqian, Clinic of Neonatal Screening and Care, Suqian, China
}

\section{WHAT IS ALREADY KNOWN ON THIS TOPIC?}

The dual oxidase maturation factor 2 (DUOXA2) and dual oxidase 2 (DUOX2) genes are rarely identified in congenital hypothyroidism $(\mathrm{CH})$.

\section{WHAT THIS STUDY ADDS?}

We detected a novel splice-site mutation in the DUOXA2 gene and a missense mutation in the DUOX2 gene in a boy with $\mathrm{CH}$.

\section{ABSTRACT}

The coexistence of mutations in the dual oxidase maturation factor 2 (DUOXA2) and dual oxidase 2 (DUOX2) genes is rarely identified in congenital hypothyroidism (CH). This study reports a boy with $\mathrm{CH}$ due to a novel splice-site mutation in the DUOXA2 gene and a missense mutation in the DUOX2 gene. A four-year-old boy was diagnosed with $\mathrm{CH}$ at neonatal screening and was enrolled in this study. The DUOXA2, DUOX2, thyroid peroxidase (TPO), and thyrotropin receptor (TSHR) genes were considered for genetic defects screening. Genomic DNA was extracted from peripheral blood leukocytes, and Sanger sequencing was used to screen the mutations in the exon fragments. Family members of the patient and the controls were also enrolled and evaluated. The boy harbored compound heterozygous mutations including a novel splice-site mutation c.554+5C>T in the maternal DUOXA2 allele and c.2654G $>A$ (p.R8850) in the paternal DUOX2 allele. The germline mutations from his parents were consistent with an autosomal recessive inheritance pattern. No mutations in the TPO and TSHR genes were detected. A novel splice-site mutation c.554+5C>T in the DUOXA2 gene and a mutation p.R8850 in the DUOX2 gene were identified in a 4-year-old patient with goitrous $\mathrm{CH}$.

Keywords: Congenital hypothyroidism, dual oxidase maturation factor 2, dual oxidase 2, mutation

Conflict of interest: None declared

Received: 02.09 .2015

Accepted: 15.11 .2015

\section{Introduction}

It is generally known that congenital hypothyroidism $(\mathrm{CH})$ is the most common neonatal endocrine disorder and occurs in approximately 1:2000-1:4000 of newborns. $\mathrm{CH}$ cases are caused by various defects including thyroid dysgenesis and thyroid hormone synthesis defects $(1,2)$. Previous studies revealed 
inactivating mutations in a specific subtype of $\mathrm{CH}$. Of the known genes, mutations in dual oxidase maturation factor 2 (DUOXA2), dual oxidase 2 (DUOX2), thyroid peroxidase (TPO), and thyrotropin receptor (TSHR), that are all known to be related to thyroid dysgenesis or dyshormonogenesis and that are all inherited in an autosomal recessive pattern, have been reported $(3,4,5,6)$.

The existing data suggest that inactivating mutations in the TSHR gene are responsible for thyrotropin (TSH) resistance and thyroid dysgenesis $(1,2,6,7)$. Mutations in the DUOXA2, DUOX2, and TPO genes are responsible for thyroid dyshormonogenesis and goitrous congenital hypothyroidism $(\mathrm{GCH})(3,4,5)$. Defective thyroid hormone synthesis represents most cases of GCH. Mutations in the DUOXA2, DUOX2, TPO, and TSHR genes are more common than those in thyroglobulin (TG) and paired box 8 (PAX8) genes in $\mathrm{CH}(1,2)$.

Currently, it is believed that $\mathrm{H}_{2} \mathrm{O}_{2}$ generation needs the catalytic core of DUOX2. Oxidation reaction is crucial for the iodination of TG during thyroid hormone synthesis. DUOXA2 is required for normal DUOX2 enzymatic activity. It has been identified that DUOXA2 is crucial for DUOX2 maturation, and genetic defects in DUOX2 cause $\mathrm{CH}$ and subclinical another important candidate gene for $\mathrm{CH}$ and $\mathrm{SCH}(3,4,8,9,10)$.

To date, the genetic defects in $\mathrm{CH}$ have not been fully understood. In this study, the DUOXA2, DUOX2, TPO, and TSHR genes were considered for screening genetic defects in a male patient with $\mathrm{GCH}$ reported below.

\section{Case Report}

A four-year-old boy came from the city of Suqian in Jiangsu Province, China. He had been diagnosed as $\mathrm{CH}$ at the neonatal screening and treatment was initiated. He was recruited by our team for investigation of a possible mutation. The patient was born to non-consanguineous parents without thyroid disease. $\mathrm{CH}$ was diagnosed on the basis of serum $\mathrm{TSH}$, free thyroxine $\left(\mathrm{fT}_{4}\right)$, and free triiodothyronine $\left(\mathrm{fT}_{3}\right)$ levels. Daily L-thyroxine was administered to the patient at diagnosis. Thyroid gland examinations were performed with 99mTc thyroid scan and ultrasound at age four years. A total of 105 unrelated healthy controls were enrolled in this study. This study was approved by the ethics committee of the hospital. Written informed consent was obtained. Blood samples were collected from the participants.

At the beginning of the study, venous blood samples were obtained from the boy. DNA was extracted from peripheral blood leukocytes. Primers were designed to target the flanking intron regions of the exons. All exons of the DUOXA2 (MIM\# 612772, GenBank NM_207581.3), DUOX2 (MIM\# 606759, GenBank NM_014080.4), TPO (MIM\# 606765, GenBank NM_000547.5), and TSHR (MIM\# 603372, GenBank NM_000369.2) genes were amplified by polymerase chain reaction (PCR). The amplified PCR products were Sanger sequenced directly for variance analysis. All exons of the above genes were first amplified in the patient. If a mutation was identified, the target fragment was also amplified in the patient's parents and in 105 control individuals. Novel mutations were analyzed by bioinformatic tools.

The clinical summary and thyroid function of the boy and his parents are shown in Table 1. The proband had overt $\mathrm{CH}$ at neonatal screening. L-thyroxine was the treatment of choice at diagnosis, with a starting dose of $10 \mu$ was the treatment of choice at diagnosis, with a starting dose of $10 \mathrm{~s}$ are shown in Table 1. The proband had. Thyroid function tests showed that the parents had normal thyroid function. Thyroid ultrasound examination demonstrated enlarged thyroid lobes in our patient. Thyroid 99mTc scan revealed that the boy's thyroid appeared normally located but enlarged (Figure 1, Panel A).

As shown in Figure 2, the genetic analysis demonstrated two heterozygous mutations, a novel maternal allele splicing site variant (c.554+5C>T) (C to T substitution at position +5 of the donor site of intron 4) in the DUOXA2 gene and another paternal allele missense mutation c.2654G $>A$ (p.R8850) in the exon 20 of the DUOX2 gene, which has been reported previously (3). No mutations in the TPO and TSHR genes were detected in this study. None of the controls showed the same pathogenic variants.

The splicing site variant c.554+5C>T at the exon 4/intron 4 junction of the DUOXA2 was not present in the Human Gene Mutation Database, nor in the dbSNP database, 1000 Genomes Project database, or PubMed. The splicing variant prediction was carried out using Human Splicing Finder, Alternative Splice Site Predictor, and SplicePort. The prediction results showed that the variant might alter gene splicing by removing the normal splice donor at the abnormal site (potential splice site: ATGgtaagc, consensus value: 92.12) or (constitutive donor: TAAAGTTCCTgtaagtatta, score: 13.255; constitutive acceptor: tgtctcccagGAATCTCCCT, score: 9.038) or (donor short sequence: ttcctgtaagta, score: 1.59992; donor short sequence: ttcctgtattaa, score: -0.995081$)$, respectively. We concluded that the c.554+5C>T might lead to intron 4 splicing loss and altered DUOXA2 messenger ribonucleic acid (RNA) sequence and the protein primary structure.

\begin{tabular}{|l|l|l|l|l|}
\hline Table 1. Clinical and biochemical data of the family in May 2015 \\
\hline Variables & $\begin{array}{l}\text { Normal } \\
\text { range }\end{array}$ & Patient $^{\phi}$ & Mother & Father \\
\hline Age (years) & $/$ & 4 & 28 & 30 \\
\hline Height (cm) & $/$ & 108 & 160 & 169 \\
\hline Weight (kg) & $/$ & 12 & 55 & 65 \\
\hline Vision & $/$ & Normal & Normal & Normal \\
\hline Thyrotropin (mIU/mL) & $0.34-5.44$ & $>100.00$ & 1.61 & 2.80 \\
\hline $\begin{array}{l}\text { Free triiodothyronine } \\
\text { (pmol/L) }\end{array}$ & $2.92-5.93$ & 2.84 & 3.77 & 4.00 \\
\hline Free thyroxine (pmol/L) & $7.91-20.59$ & 4.47 & 15.20 & 17.52 \\
\hline Thyroid size & $/$ & Goiter & Normal & Normal \\
\hline क: thyroid function tests were performed at screening in the neonatal period \\
\hline
\end{tabular}


A
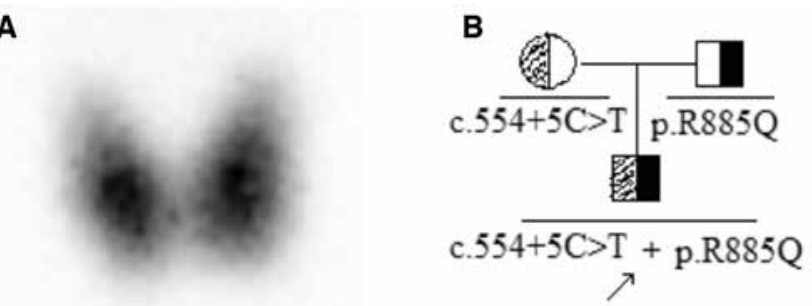

Figure 1. Thyroid $99 \mathrm{mT} \mathrm{c}$ scan revealed the enlarged thyroid lobes of the boy (Panel A, anterior view). The arrow indicating the proband in the pedigree with the compound heterozygous mutations (Panel B)

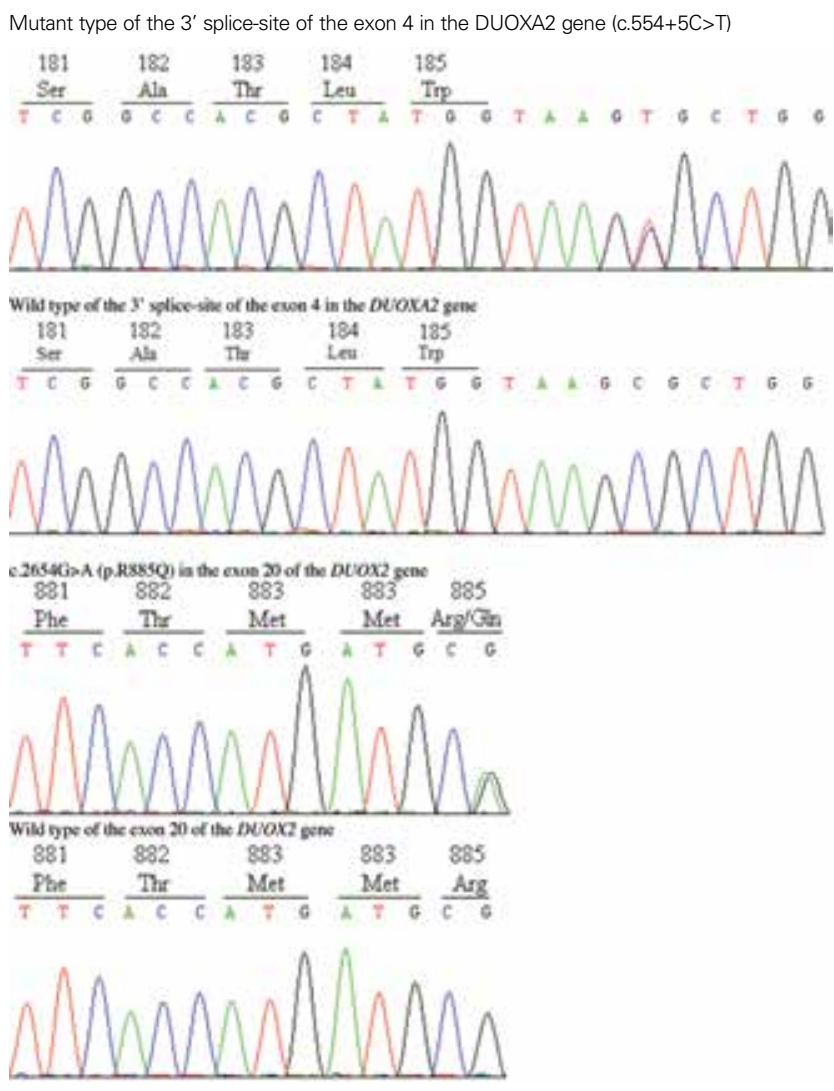

Figure 2. The genotypes revealing the heterozygous mutations in the DUOXA2 gene (c.554+5C>T) and in the DUOX2 gene (c.2654G>A, p.R8850)

\section{Discussion}

The present study demonstrated compound heterozygous mutations, c.554+5C>T in the DUOXA2 gene and c.2654G>A (p.R8850) in the DUOX2 gene in a pedigree with one four-yearold boy with $\mathrm{GCH} . \mathrm{H}_{2} \mathrm{O}_{2}$ is a key element in iodine organification. DUOXA2/DUOX2 is the main enzyme for the $\mathrm{H}_{2} \mathrm{O}_{2}$-generating system. Defects in the DUOX2/DUOXA2 heterodimer lead to hypothyroidism and goiter. Since the first report in 2002 of DUOX2 mutations causing $\mathrm{CH}(10,11)$, over 40 mutations in the
DUOX2 gene have been described correlated with $\mathrm{CH}$, while only four mutations have been identified in the DUOXA2 gene $(3,8,9,10)$. Thus far, our splice site mutation, as far as we know, is identified for the first time as being causative of $\mathrm{CH}$.

The patients with DUOX2 or DUOXA2 mutation show a great genotype-phenotype variability $(10,11)$. Maruo et al (3) firstly reported the p.R8850 mutation in the DUOX2 gene exhibiting transient hypothyroidism, which is not similar to our patient. The patient in this study had permanent $\mathrm{CH}$ and needed L-thyroxine replacement therapy. Heterozygous DUOX2 gene mutations result in different phenotypes, such as transient $\mathrm{CH}$, subclinical hypothyroidism, and euthyroidism. However, the coexistence of heterozygous TSHR and DUOXA2 mutations causes overt hypothyroid condition (12).

Four mutations in the DUOXA2 (p.I26M, p.Y138X, p.C189R and p.Y246X) were found to be associated with $\mathrm{CH}(3,4,8,9,10)$. The patient with the p.I26M, p.C189R, and p.Y138X heterozygous missense mutation in DUOXA2 gene presented as a mild transient $\mathrm{CH}$ case. A homozygous nonsense mutation (p.Y246X) in patients with mild permanent $\mathrm{CH}$ and goiter was also identified. These patients are all of Chinese origin, indicating that this specific variant may occur at a high frequency in Chinese cohorts with $\mathrm{CH}$.

Splice-site mutations are important disease-causing defects. It is estimated that approximately $10 \%$ of human genetic diseases are caused by mutations at splice sites (13). Analysis of the c.554+5C>T variation in the DUOXA2 gene revealed that it is capable of causing disease. Possibly this is the first report of a c.554+5C>T mutation in the DUOXA2 gene. The proband in this study presented with a normally located but enlarged thyroid gland. His parents, each with a single heterozygous mutation, both exhibited normal thyroid positioning and normal serum thyroid hormone levels. Our patient demonstrated no physical or cognitive developmental defects, primarily due to the timely and effective treatment.

Additionally, the c.554+5C>T mutation may affect the RNA transcription process and lead to genetic instability of the DUOXA2 gene. Further comprehensive functional assessments of the detected mutation will reveal its exact mechanism in the pathogenesis of $\mathrm{CH}$. The R434X mutation in the DUOXA2 was detected by a two-stage strategy of genetic linkage studies and targeted sequencing of the candidate genes, suggesting a new testing strategy which uses nextgeneration sequencing in $\mathrm{CH}$ cases (14).

In conclusion, the present study reports a novel splicing site variant $(c .554+5 \mathrm{C}>\mathrm{T})$ in the DUOXA2 gene and another missense mutation c. $2654 \mathrm{G}>\mathrm{A}$ (p.R8850) in the DUOX2 gene. The findings indicate the importance of molecular genetic studies for the accurate diagnosis and classification of $\mathrm{CH}$. 


\section{Acknowledgments}

We thank the patient and his family members who agreed to participate in this study.

\section{Ethics}

Ethics Committee Approval: Huai'an Second People's Hospital Ethics Committee (Approval number: 05-23-2014), Informed Consent: It was taken.

Peer-review: External peer-reviewed.

\section{Authorship Contributions}

Concept: Shao-Gang Ma, Design: Shao-Gang Ma, Data Collection or Processing: Xiao Zheng, Ya-Li Oiu, Analysis or Interpretation: Man-Li Guo, Xiao-Juan Shao, Literature Search: Man-Li Guo, and Xiao-Juan Shao, Writing: Xiao Zheng and ShaoGang Ma.

Financial Disclosure: The authors declared that this study was supported by the Social Development Project of Huai'an City (grant number: HAS2014005) and the Social Development Project of Suqian City (grant number: Z201460).

\section{References}

1. Chiesa A, Prieto L, Mendez V, Papendieck P, Calcagno Mde L, Gruñeiro-Papendieck L. Prevalence and etiology of congenital hypothyroidism detected through an argentine neonatal screening program (1997-2010). Horm Res Paediatr 2013;80:185-192.

2. Szinnai G. Genetics of normal and abnormal thyroid development in humans. Best Pract Res Clin Endocrinol Metab 2014;28:133-150. Epub 2013 Aug 20

3. Maruo $Y$, Takahashi $H$, Soeda I, Nishikura N, Matsui K, Ota Y, Mimura Y, Mori A, Sato H, Takeuchi Y. Transient congenital hypothyroidism caused by biallelic mutations of the dual oxidase 2 gene in Japanese patients detected by a neonatal screening program. J Clin Endocrinol Metab 2008;93:42614267. Epub 2008 Sep 2

4. Zamproni I, Grasberger H, Cortinovis F, Vigone MC, Chiumello G, Mora S, Onigata K, Fugazzola L, Refetoff S, Persani L, Weber $\mathrm{G}$. Biallelic inactivation of the dual oxidase maturation factor 2 (DUOXA2) gene as a novel cause of congenital hypothyroidism. J Clin Endocrinol Metab 2008;93:605-610. Epub 2007 Nov 27

5. Ris-Stalpers C, Bikker H. Genetics and phenomics of hypothyroidism and goiter due to TPO mutations. Mol Cell Endocrinol 2010;322:38-43. Epub 2010 Feb 12

6. Cangul H, Aycan Z, Saglam H, Forman JR, Cetinkaya S, Tarim O, Bober E, Cesur Y, Kurtoglu S, Darendeliler F, Bas V, Eren E, Demir K, Kiraz A, Aydin BK, Karthikeyan A, Kendall M, Boelaert K, Shaw NJ, Kirk J, Högler W, Barrett TG, Maher ER. TSHR is the main causative locus in autosomal recessively inherited thyroid dysgenesis. J Pediatr Endocrinol Metab 2012;25:419-426.

7. Ma SG, Fang PH, Hong B, Yu WN. The R450H mutation and D727E polymorphism of the thyrotropin receptor gene in a Chinese child with congenital hypothyroidism. J Pediatr Endocrinol Metab 2010;23:1339-1344.

8. Hulur I, Hermanns P, Nestoris C, Heger S, Refetoff S, Pohlenz $\mathrm{J}$, Grasberger $\mathrm{H}$. A single copy of the recently identified dual oxidase maturation factor (DUOXA) 1 gene produces only mild transient hypothyroidism in a patient with a novel biallelic DUOXA2 mutation and monoallelic DUOXA1 deletion. J Clin Endocrinol Metab 2011;96:841-845. Epub 2011 Mar 2

9. Yi RH, Zhu WB, Yang LY, Lan L, Chen Y, Zhou JF, Wang J, Su YQ. A novel dualoxidase maturation factor 2 gene mutation for congenital hypothyroidism. Int J Mol Med 2013;31:467470. Epub 2012 Dec 24

10. O'Neill S, Brault J, Stasia MJ, Knaus UG. Genetic disorders coupled to ROS deficiency. Redox Biol 2015;6:135-156. Epub $2015 \mathrm{Jul} 17$

11. Moreno JC, Bikker $H$, Kempers MJ, van Trotsenburg AS, Baas F, de Vijlder JJ, Vulsma T, Ris-Stalpers C. Inactivating mutations in the gene for thyroid oxidase 2 (THOX2) and congenital hypothyroidism. N Engl J Med 2002;347:95-102.

12. Satoh $M$, Aso $K$, Ogikubo $S$, Yoshizawa-Ogasawara $A$, Saji T. Hypothyroidism caused by the combination of two heterozygous mutations: one in the TSH receptor gene the other in the DUOX2 gene. J Pediatr Endocrinol Metab 2015;28:657-661.

13. Stenson PD, Mort M, Ball EV, Howells K, Phillips AD, Thomas NS, Cooper DN. The Human Gene Mutation Database: 2008 update. Genome Med 2009;1:13.

14. Cangul $H$, Aycan Z, Kendall M, Bas VN, Saglam Y, Barrett TG, Maher ER. A truncating DUOX2 mutation (R434X) causes severe congenital hypothyroidism. J Pediatr Endocrinol Metab 2014;27:323-327. 